\title{
ALTERATIONS IN OXIDANTS AND PHOTOSYNTHETIC PIGMENTS AS POSSIBLE DETERMINANTS OF CROSS-LOCATIONAL ADAPTABILITY POTENTIAL IN TWO LEMONGRASS (Cymbopogon citratus) POPULATIONS
}

\author{
Kanval Shaukat ${ }^{1, *}$, Abdul Wahid ${ }^{1 *}$ and Shahzad M.A. Basra ${ }^{2}$ \\ ${ }^{1}$ Department of Botany, University of Agriculture, Faisalabad 38040, Pakistan; ${ }^{2}$ Department of Agronomy, University \\ of Agriculture, Faisalabad 38040, Pakistan. \\ *Corresponding author's e-mail: kanval_shaukat777@yahoo.com; drawahid@uaf.edu.pk
}

\begin{abstract}
Lemongrass [Cymbopogon citrates (DC) Stapf] is a cosmopolitan economically important grass with a natural potential to adapt to different climates. However, the mechanisms of cross-locational adaptability are not studied in this grass species. To explore some physiological basis of cross-locational adaptability potential of lemongrass, experiments were performed on one population each from Faisalabad and Quetta, Pakistan. Both the population were planted at both the locations in a reciprocal swap arrangement using randomized complete block design with three replicates. The data were recorded on monthly basis from June to December over two consecutive years (2015 and 2016). The swap reciprocated lemongrass populations from Quetta and Faisalabad exhibited differential growth patterns from their native counterparts thus showing flexibility among the populations. Enhanced tillering, root proliferation and increased dry shoot and root weight was observed in the Quetta population adapted in Faisalabad. However, Faisalabad population adapted in Quetta produced taller plants with longer roots, while tillering and number of leaves were greatly reduced in the Quetta adapted population as compared to its counterpart in Faisalabad. Tissue analysis for hydrogen peroxide $\left(\mathrm{H}_{2} \mathrm{O}_{2}\right)$ and malondialdehyde (MDA) data revealed that both the native and adapted populations in Faisalabad accumulated greater $\mathrm{H}_{2} \mathrm{O}_{2}$ and MDA in summer months while Quetta population did so in the winter months, thus showing that summer months in Faisalabad and winter months in Quetta to be stressful for the populations in the respective locations. Both native and adapted populations in Quetta displayed dark green leaf color, which was accompanied by increased chlorophyll $a$ and $b$ contents in summer months in Quetta and winter months in Faisalabad, while carotenoids accumulation was greater in the season with high temperature in Faisalabad and chilling temperature in Quetta. Fitting regression equation and finding correlation between maximum and minimum temperatures and relative humidity $(\mathrm{RH})$ revealed negative correlations of temperatures with growth, $\mathrm{H}_{2} \mathrm{O}_{2}$ and MDA at both the locations in native and adapted population, while positive correlation of chlorophylls and carotenoids at Quetta and negative ones at Faisalabad, while $\mathrm{RH}$ was regressed with none of these attributes (data not shown). This implied that temperature was a major determining factor in the adaptation of populations at either location based on flexibility in physiological adjustments at both the locations.

Keywords: Root length, tillering, oxidative damage, carotenoids, cross-adaptability, lemongrass
\end{abstract}

\section{INTRODUCTION}

In the present day world, climate change has emerged as an adverse factor for living organisms. It threatens the survival of plant and animal species due to increase in mean temperature and extreme weather conditions. As a result, species respond differently to changing climates. It may a) die out locally, b) shift its habitat range to higher altitudes/latitudes or c) adapt itself to changing conditions (Lenoir et al., 2008). The expression of adaptive characters is due to genetic variations under specific environmental conditions (Andrew et al., 2010); otherwise plant adopt by showing phenotypic plasticity i.e., a single genotype expressing different phenotype under different environmental conditions (Crispo, 2008). The phenotypic plasticity rather than genetic diversity plays a key role in the adaptability of a plant to thrive in an environment (Vitasse et al., 2010; Grenier et al., 2016). The adaptability acts as a shield to overcome harsh environmental conditions (Jump and Penuelas, 2005). The plants not only show variations in their morphological attributes but also display physiological and biochemical versatility, which ensure their survival (Dat et al., 2000). So, different environments favor unique and specific flora in any area (Anderson et al., 2011).

Adjustment to changing climate and building resilience among organisms to react to climatic threats is rather novel concepts (Sarfaraz et al., 2014). Relationships among natural selection, adaptive genetic variation, gene flow and plasticity are complex and the hotspot of interest in evolutionary ecology (Crispo, 2008). Exploring the genetic and physiologic mechanisms underlying cross-locational adaptability may help improve our understanding of survival of plants in any area (Streb et al., 2008). 
Reciprocal swapping of plants from a fully adapted native environment to a new one causes various adaptable changes to let plant survive successfully as they had prior resilience when managing the environment in an area and got fully armed to survive. During cross adaptation, a plant species produces specific metabolites to adjust to changed climates (Gong et al., 2001). Moreover, it also depends upon the ontogenetic development and the stress types or their applied levels (Zhang et al., 2006). To determine a unique response to a specific stress is a very difficult process, because a single stress may have several impacts on plants and different stresses may regulate the same target (Lutts, 2001). Nevertheless, changes in enzymatic activities remain a key factor to measure responses of an alien plant species (Cramer et al., 2011). Antioxidants and several secondary metabolites act as lines of defense under stress conditions, thus helping the plant to cope with harsh conditions more efficiently (Kasote et al., 2015).

Temperature is one of the most important factors that determines the distribution of species around the globe. A minor change in the temperature may alter the ecosystem and challenge the survival of species. It is among the main factors in phenological, distributional and physiological adaptations in plants (Vitasse et al., 2010; Rather et al., 2018). Increase in temperature reduces the time period from sowing to harvest by hastening the plant development whilst reducing the biomass yield (Hertel et al., 2010). In photosynthesis, availability of $\mathrm{CO}_{2}$ may be a limiting factor. Reduced $\mathrm{CO}_{2}$ availability decreased the stomatal conductance, but higher atmospheric levels increased the water use efficiency (Nowak et al., 2004). Increase in canopy temperature increases the carbon availability and enhances the net photosynthesis (Song et al., 2014).

The initial effect of abiotic and biotic factors on plants is the outburst of reactive oxygen species (ROS) including superoxide, singlet oxygen, hydroxyl radical and hydrogen peroxide (Mittler, 2002). They have the tendency to damage membranes by causing lipid peroxidation and denature various important biomolecules such as proteins, hormones and nucleic acids (Farooq et al., 2009; Gill et al., 2015). Hydroxyl radical is a highly lethal while hydrogen peroxide $\left(\mathrm{H}_{2} \mathrm{O}_{2}\right)$ is the most stable among the ROS (Wahid et al., 2014). In low concentration these ROS specifically $\mathrm{H}_{2} \mathrm{O}_{2}$ act as secondary messenger under stress (Slesak et al., 2007).

Adverse effects of environmental stresses are usually accompanied with a loss of photosynthetic pigments. Chlorophylls, as primary plant pigments, are involved in conversion of harnessed solar energy into chemical energy (Taiz et al., 2015). Wahid (2007) reported an increase in chlorophyll $a: b$ ratio and a decrease in chlorophyll ' $b$ ' content under heat stress in sugarcane. Abiotic stresses such as high solar radiation, strong UV-B radiation and low temperature act on high altitude alpine plants and increase the chlorophyll contents (Shi et al., 2011). Photochemical efficiency is mostly hindered under harsh environmental conditions due to the effect on photosystems especially PS-II (Murata et al., 2007). Carotenoids are accessory pigments and are lipophilic in nature. They enhance the cells and tissues stability by minimizing lipid peroxidation of membranes under both environmental and biotic stresses (Havaux, 1998). They act as a reception site of intense radiations thus protecting chlorophyll molecules from getting destroyed (Rodrigues et al., 2012). However, concentration of carotenoids worsens during different seasons of the year. Sen and Mukherji (2000) reported a decrease in carotenoid contents of tomato during rainy season. Conversely, Raffo et al. (2006) found that concentration of carotenoids did not display a fixed seasonal pattern in relation to the average temperature and solar radiations. However, no empirical relationship has been reported in the production of ROS and damage to photosynthetic pigments in the plant systems.

Lemongrass [Cymbopogon citrates (DC) Stapf] a commercially important cosmopolitan $\mathrm{C} 4$ grass due to having medicinal properties (Barbosa et al., 2008; Akhila, 2010). Being a valuable medicinal plant with diverse potential uses and its ability to grow in different ecological zones it can be used to explore the adaptive responses and chalk out the possible morphological and physiological mechanisms involved. The available studies show that lemongrass can successfully grow in different environments and shows genotypic flexibility under prevailing growing conditions, and resists well against relatively sub-optimal conditions (Prasad et al., 2001; Ng et al., 2016). It has been extensively explored for its medicinal properties, but little is known regarding the adaptive potential of lemongrass.

Locations selected for performing the current studies were Quetta and Faisalabad, which differ highly with respect to temperature, humidity, topography and soil characteristics (Shah, 1975; Chaudhary and Rasul, 2004). Biochemical mechanisms of cross-locational adaptability in plants species are poorly understood. Therefore, reciprocal swap studies on finding the cross-locational adaptability of a cosmopolitan species like lemongrass will improve our knowledge of physiological basis of lemongrass survival at diverse locations. This two years study was conducted to explore the possible involvement of changes in the growth, oxidative damage and photosynthetic pigment contents of the lemongrass population at both locations and possible interrelationships of these attributes with prevailing conditions in a reciprocal swap arrangement.

\section{MATERIALS AND METHODS}

Source of lemongrass propagules and experimental details: Field experiments were conducted to determine the crosslocational adaptability of lemongrass populations native to Faisalabad and Quetta, Pakistan locations in terms of morphological and physiological mechanisms. One 
lemongrass population one each from Quetta (Baluchistan Agricultural Research and Development Center, Arid Zone Research Institute, Quetta; $30.1798^{\circ} \mathrm{N}$ latitude and $66.9750^{\circ}$ E longitude, and $1679 \mathrm{~m}$ above sea level (m.a.s.l.)) and Faisalabad (New Botanical Garden, University of Agriculture, Faisalabad; $31.4504^{\circ} \mathrm{N}$ latitude and $73.1350^{\circ} \mathrm{E}$ longitude, respectively, and 184.4 m.a.s.l.) were reciprocally swapped to study their cross-locational adaptability. Both the populations were grown under field conditions at the respective locations. Design of experiment was Randomized Complete Block Design with three replications.

Soil characteristics: Prior to planting, the soil from both the locations was analyzed for physicochemical characteristics following the standard procedures (Hussain et al., 2010). Vast differences were observed in the physicochemical properties of soil samples obtained from Quetta and Faisalabad. Of these, Faisalabad soil was much more fertile because of its higher organic matter and $\mathrm{P}$ contents; however, $\mathrm{K}$ contents was higher in the Quetta soil samples while $\mathrm{NO}_{3}{ }^{-} \mathrm{N}$ contents were similar in the soil from both the regions. Saturation percentage of Faisalabad soil was lower than Quetta whereas the soil of Quetta was more alkaline as compared to Faisalabad due to the presence of more amount of lime. Similarly, the electrical conductivity of soil extract (ECe) was lower in Faisalabad soil when compared to Quetta soil. Sodium availability in Quetta soil was higher than that of Faisalabad soil. The $\mathrm{HCO}_{3}{ }^{-}$content of soil was greater in Quetta than in Faisalabad soil, due to the calcareous nature of soil in Quetta. In Faisalabad soil $\mathrm{Cl}^{-}$concentration was higher than the Quetta soil. Furthermore, a higher $\mathrm{Ca}+\mathrm{Mg}$ contents were observed in Quetta soil samples. Besides sodium adsorption ratio (SAR) was also higher in Quetta soils (Table 1).

Weather data: Maximum and minimum temperature data for the experimental years 2015 and 2016 for Faisalabad were obtained from the Weather Observatory, Department of Agronomy, University of Agriculture Faisalabad; while that of Quetta region was obtained from Pakistan Meteorological Department, Quetta (Table 2).

Plant measurements: Data for various growth attributes were taken during both experimental years in each region for both native and adapted populations on monthly basis, starting from Jun to Dec in both the years. Growth parameters like plant height, leaf area, root length were measured using measuring tape. Samples were oven dried at $65^{\circ} \mathrm{C}$ for seven days for the determination of dry weights of both shoot and root. Data regarding number of tillers, number of leaves and roots per plant were also taken under consideration during both experimental years.

Measurement of oxidative stress: The $\mathrm{H}_{2} \mathrm{O}_{2}$ contents were determined by Velikova et al. (2000) method. Fresh leaf samples $(0.1 \mathrm{~g})$ were grinded with $5 \mathrm{~mL}$ of $0.1 \%(\mathrm{w} / \mathrm{v})$ trichloroacetic acid (TCA) in pre-chilled microfuge tubes by crushing the tissues while cool (placed on ice bath). The homogenized material was then centrifuged at $12000 \mathrm{rpm}$ for $15 \mathrm{~min}$. The supernatant $(0.5 \mathrm{~mL})$ was mixed with $0.5 \mathrm{~mL}$ of potassium phosphate buffer $(\mathrm{pH} 7.0)$ and $1 \mathrm{~mL}$ of potassium iodide solution, thoroughly mixed and absorbance was recorded at $390 \mathrm{~nm}$. Distilled water was used as blank. The $\mathrm{H}_{2} \mathrm{O}_{2}$ in the test samples was determined by constructing a standard curve.

The MDA was measured by the method of Heath and Packer (1968). A $0.1 \mathrm{~g}$ of fresh plant material was grinded in $1 \mathrm{~mL}$ of $1 \%$ TCA solution and then centrifuged for $15 \mathrm{~min}$. To $1 \mathrm{~mL}$ of supernatant, $1 \mathrm{~mL}$ of $0.5 \%$ thiobarbaturic acid prepared in $20 \%$ TCA was added followed by heating at $100^{\circ} \mathrm{C}$. The reaction mixture was centrifuged at $7500 \times g$ for $5 \mathrm{~min}$. The samples were incubated for $50 \mathrm{~min}$ at $95^{\circ} \mathrm{C}$ and cooled in ice

Table 1. Physicochemical characteristics of soil samples from Quetta and Faisalabad locations.

\begin{tabular}{|c|c|c|c|c|c|c|c|c|c|c|c|c|}
\hline \multirow[t]{3}{*}{ Region } & \multirow{2}{*}{\multicolumn{3}{|c|}{$\frac{\text { AB-DTPA Extractable }}{(\mathrm{mg} / \mathrm{kg})}$}} & \multirow{2}{*}{\multicolumn{2}{|c|}{ (\%) }} & \multicolumn{6}{|c|}{ 1:1 Ratio } & \multirow[t]{3}{*}{ SAR } \\
\hline & & & & & & \multicolumn{3}{|c|}{$(\mathrm{dS} / \mathrm{m})$} & \multicolumn{2}{|c|}{$(\mathrm{mg} / \mathrm{kg})$} & \multirow[b]{2}{*}{$\mathrm{Ca}+\mathrm{Mg}$} & \\
\hline & $\mathbf{P}$ & K & $\mathrm{NO}_{3}-\mathrm{N}$ & O.M & SP & pH & EC & $\mathrm{Na}+$ & $\mathrm{HCO}_{3-}$ & Cl- & & \\
\hline Quetta & 1.56 & 184 & 0.285 & 0.532 & 39.815 & 8.155 & 1.35 & 6.837 & 2.95 & 5.75 & 18.15 & 2.54 \\
\hline Faisalabad & 2.24 & 162 & 0.285 & 1.100 & 38.555 & 8.045 & 0.435 & 1.747 & 2.625 & 1.675 & 4.175 & 1.165 \\
\hline
\end{tabular}

Table 2. Month-wise average temperature (Av. Temp) and relative humidity (RH) of Quetta and Faisalabad locations recoded during the years 2015 and 2016.

\begin{tabular}{lcccccccc}
\hline Months & \multicolumn{2}{c}{ Faisalabad 2015 } & \multicolumn{2}{c}{ Faisalabad 2016 } & \multicolumn{2}{c}{ Quetta 2015 } & \multicolumn{2}{c}{ Quetta 2016 } \\
\cline { 2 - 8 } & Av. Temp $\left({ }^{\circ} \mathbf{C}\right)$ & RH $(\%)$ & Av. Temp $\left({ }^{\circ} \mathbf{C}\right)$ & RH $(\%)$ & Av. Temp $\left({ }^{\circ} \mathbf{C}\right)$ & RH $(\%)$ & Av. Temp $\left({ }^{\circ} \mathbf{C}\right)$ & RH $(\%)$ \\
\hline June & 31.79 & 38.96 & 34.35 & 6.80 & 26.88 & 46.76 & 28.77 \\
July & 31.02 & 60.46 & 32.13 & 5.28 & 28.15 & 54.06 & 30.50 \\
August & 31.33 & 60.66 & 30.75 & 5.12 & 26.77 & 51.83 & 29.67 & 14.96 \\
September & 29.86 & 69.63 & 31.00 & 6.35 & 21.58 & 57.50 & 24.67 \\
October & 25.75 & 52.56 & 26.77 & 8.54 & 18.83 & 47.23 & 17.28 \\
November & 19.58 & 61.49 & 20.11 & 8.71 & 11.64 & 60.63 & 11.18 \\
December & 14.48 & 62.63 & 16.38 & 8.33 & 6.34 & 63.03 & 10.53 \\
\hline
\end{tabular}


bath. The absorbance of supernatant was measured at $532 \mathrm{~nm}$ and $600 \mathrm{~nm}$, while $1 \%$ TCA (w/v) was used as blank. Nonspecific turbidity was corrected by subtracting the $\mathrm{A}_{600}$ from that of $A_{532}$. An extinction coefficient of $155 \mathrm{nmol} / \mathrm{L}$ was used to calculate the amount of MDA in the samples using the following equation:

MDA equivalents ( $\left.\mathrm{nmol} \mathrm{mL}^{-1}\right)$

$$
=[(\mathrm{A} 532-\mathrm{A} 600) / 155000] \times 10^{6}
$$

Photosynthetic pigment contents: Chlorophyll $a$ and $b$ contents were determined using the method of Arnon (1949) while carotenoids were determined using the standard protocol of Davies (1976). For this purpose, $0.1 \mathrm{~g}$ fresh leaves material was extracted with $80 \%$ acetone. Extract was filtered and made the final volume up to $10 \mathrm{~mL}$ with $80 \%$ acetone. Absorbance of samples were measured at 663, 645 and 480 nm using a spectrophotometer. The chlorophylls $a$ and $b$ contents and their total, and carotenoids contents were determined using the following formulae:

Chlorophyll $a$ (mg/g fresh wt.) $=(1.27($ OD663 $)-2.69($ OD645 $) \times \mathrm{V} / 1000 \times \mathrm{W}$

Chlorophyll $b$ (mg/g fresh wt.) $=(22.9($ OD645 $)-4.68($ OD663 $) \times \mathrm{V} / 1000 \times \mathrm{W}$

Total chlorophyll (mg/g fresh wt.) $=(20.2($ OD645 $)+8.02($ OD 663$) \times \mathrm{V} / 1000 \times \mathrm{W}$

Carotenoids (mg/g fresh wt.)

$=(\mathrm{OD} 480+0.114(\mathrm{OD} 663)-0.638(\mathrm{OD} 645) / 2500) \times 1000$ Statistical analysis: The experiment was laid out in Randomized Complete Block Design with three replications. The data were subjected to statistical analysis using two-way analysis of variance (Steel et al., 1996). The treatment means were compared using LSD test. The treatment means for each parameter were compared by putting letters on them where the overall interaction of various factors was significant $(\mathrm{P}<0.05)$. The regression equations were fitted and correlation coefficients computed of the ambient temperature and $\mathrm{RH}$ with different growth and physiological characters.

\section{RESULTS}

Growth characters: The data regarding growth parameters of lemongrass populations at Quetta and Faisalabad region (native and adapted) during 2015 and 2016 revealed that plant height, root length, number of roots per plant, leaf area, shoot and root dry weights showed significant differences $(\mathrm{P}<0.05)$. Faisalabad adapted and Quetta native populations exhibited maximum height as compared to other two populations under investigation. The Quetta populations (native and adapted) had longer roots as compared to Faisalabad populations during both the experimental years. However, when Faisalabad lemongrass population was swapped to Quetta it produced taller plants as compared to its counterpart at Faisalabad (Fig. 1). Considering number of tillers, leaves and roots per plants, the Faisalabad climate enhanced these attributes both in native and adapted populations while Quetta climate reduced tillering and root proliferation. Quetta population and its population adapted in Faisalabad (Faisalabad adapted) displayed greater leaf area. Conversely, Quetta adapted population showed increased leaf area as compare to its counterpart at Faisalabad. Dry biomass (of both shoot and root) was significantly higher in the Faisalabad populations (native and adapted) revealing that edaphic and environmental conditions enhanced root and shoot biomass, which was substantially reduced under Quetta climate.

Oxidative stress measurement: Oxidative parameters showed significant differences among different lemongrass population $(\mathrm{P}<0.05)$. Hydrogen peroxide (a representative ROS species) in shoot and root of lemongrass populations was enhanced under harsh environmental conditions in adapted lemongrass population at both regions. Summer acted as harsh climate for Faisalabad adapted lemongrass population enhancing MDA and hydrogen peroxide in both shoot and roots where the native population survived successfully. Similarly, chilling/freezing winter of Quetta resulting in more enhanced $\mathrm{H}_{2} \mathrm{O}_{2}$ and MDA levels in adapted population as compared to the native population of the region (Fig. 2).

Photosynthetic pigments contents: Lemongrass populations at Quetta (native and adapted) displayed maximum chlorophyll $a$ and $b$ contents as compared to Faisalabad lemongrass populations. Summer season led to biosynthesis of higher chlorophyll $a$ and $b$ content in all lemongrass population that tend to decline gradually on the onset of winter season during both the experimental years. Quetta native and adapted population accumulated more total chlorophyll than Faisalabad's lemongrass population depicting the darker green leaf color in the native and adapted populations. Carotenoid content showed significant difference among different lemongrass population. However, carotenoid contents were higher under adverse climatic conditions in the respective region. Summer resulted in the biosynthesis of high carotenoid content in Faisalabad adapted and Quetta native populations while winter months accumulated higher carotenoid in Faisalabad native and Quetta adapted populations (Fig. 3).

Correlations: Both high and low temperatures have specific effects on the growth and metabolism of all the plant species. Leaf area per plant, root length, number of roots per plant, number of leaves per plant, shoot and root dry weight, carotenoids, MDA (shoot and root), hydrogen peroxide (shoot and root) showed negative correlations with minimum and maximum temperatures during one or both the experimental years. However, parameters like, chlorophyll $a, b$, carotenoids, total chlorophylls, shoot and root MDA and $\mathrm{H}_{2} \mathrm{O}_{2}$ showed positive correlations either with all four or in one or the other lemongrass populations (Table 3).

Leaf area, number of leaves per plant, carotenoids and $\mathrm{H}_{2} \mathrm{O}_{2}$ (shoot and root) in Faisalabad native and Quetta adapted populations showed strong negative correlations in both the experimental years. Number of tillers per plant in Faisalabad 


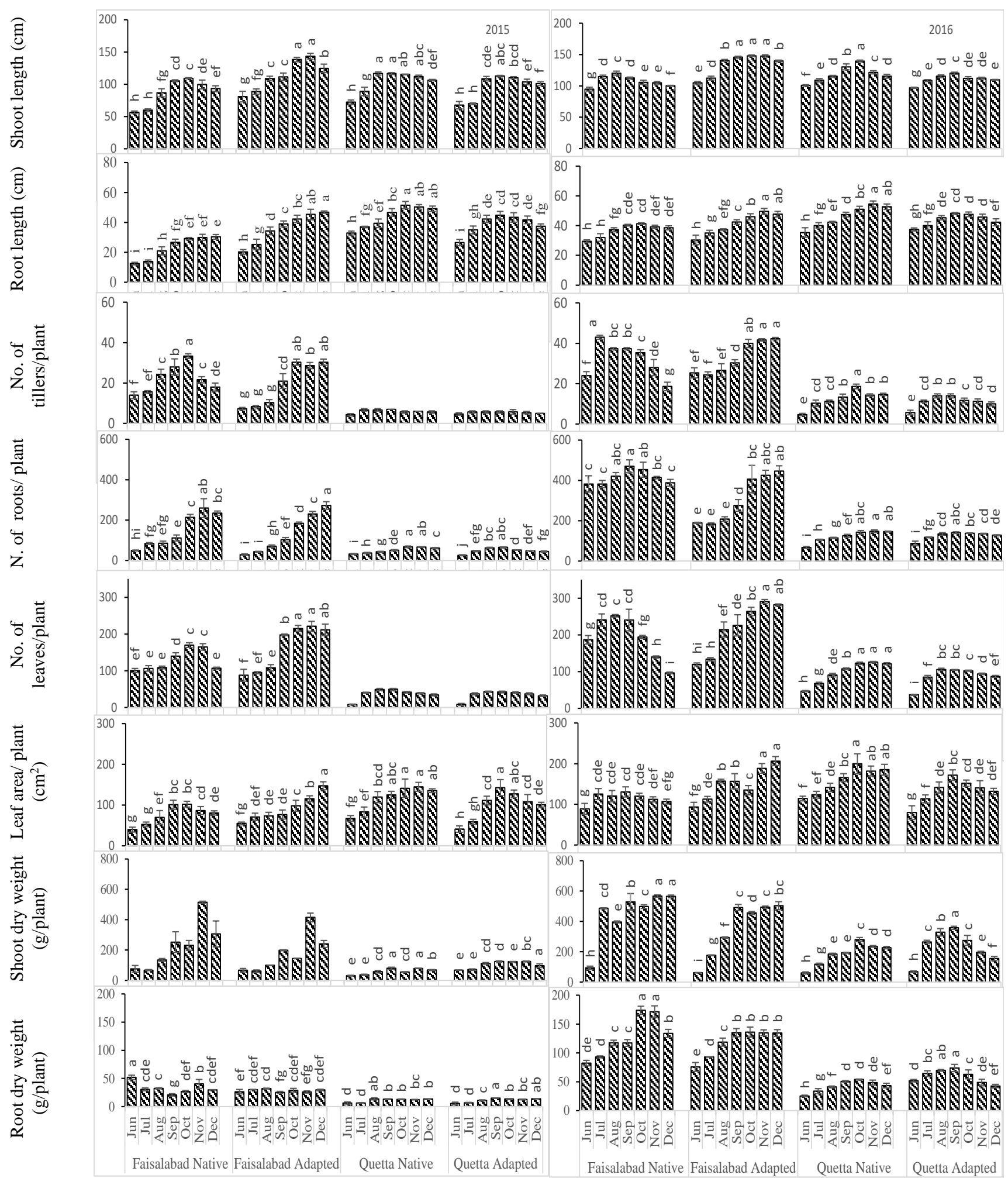

Figure 1. Differences in some growth characteristics of native and adapted lemongrass populations from Faisalabad and Quetta studied during 2015 and 2016 planted in reciprocal swap arrangement. 


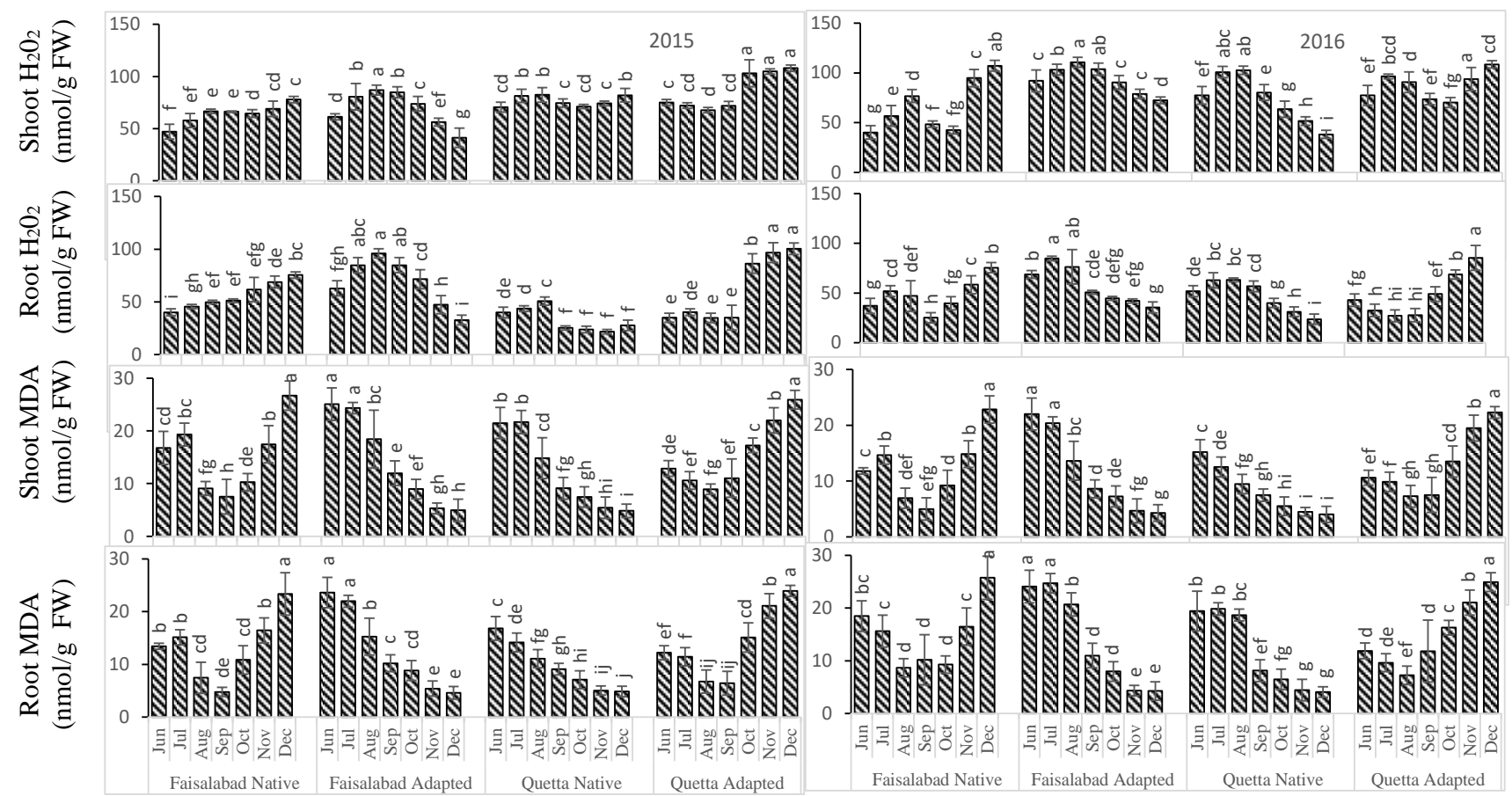

Figure 2. Comparative changes in the hydrogen peroxide and malondialdehyde concentrations of native and adapted lemongrass populations from Faisalabad and Quetta during 2015 and 2016 planted in reciprocal swap arrangement.
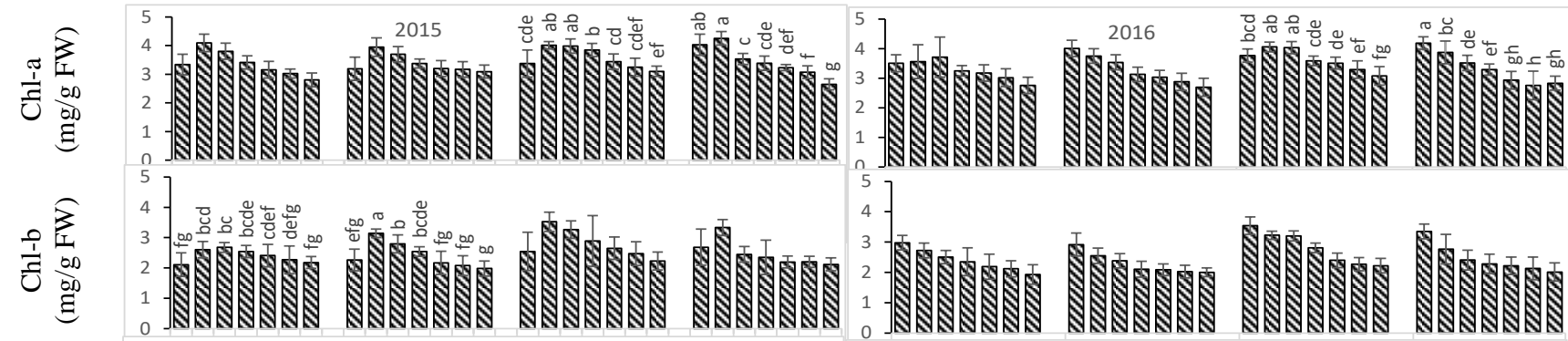

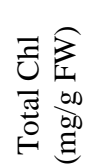
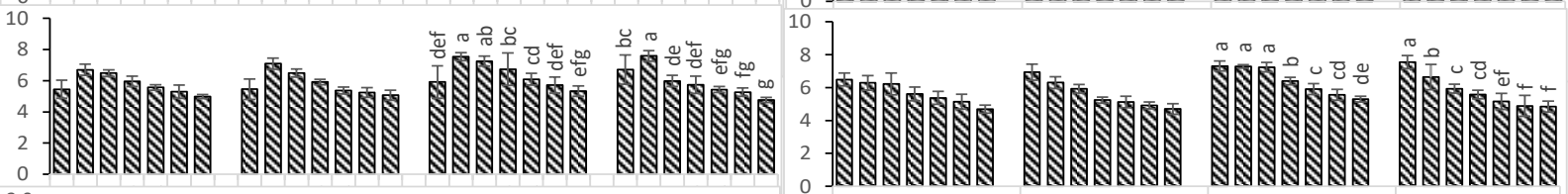

$$
\text { 胥 }
$$
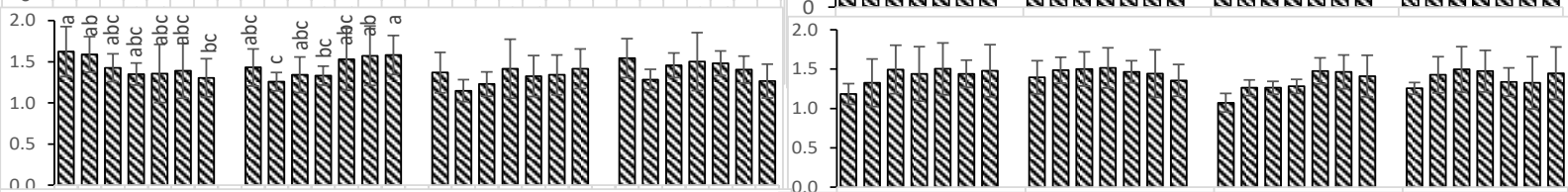

$$
\text { U. }
$$
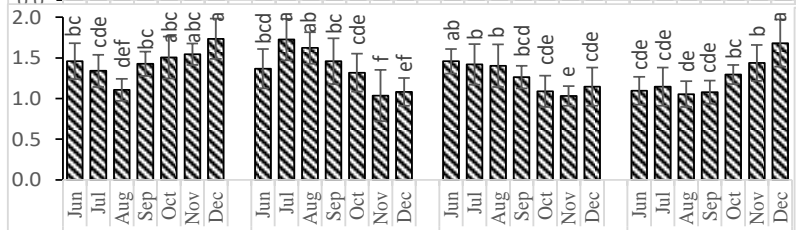

2.0
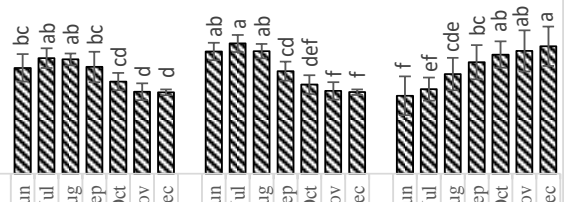

Faisalabad Native Faisalabad Adapted

Quetta Native

Quetta Adapted

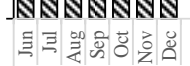

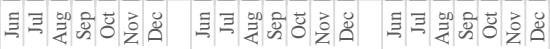

Figure 3. Comparative changes in the photosynthetic pigment contents of native and adapted lemongrass populations from Faisalabad and Quetta during 2015 and 2016 planted in reciprocal swap arrangement. 
adapted lemongrass population showed a significant negative correlation with minimum and maximum temperature in 2016, while in 2015, number of tillers per plant showed nonsignificant relationship with maximum temperature (Table 3). Root length, Number of roots per plant and shoot dry weight displayed negative correlations in all the lemongrass populations (except Quetta adapted population for root length, number of roots per plant) with both minimum and maximum temperature of the respective region during both the study years. Root length in Quetta native and Faisalabad adapted population showed strong negative correlations during the year 2016 as compared to 2015, while an opposite trend was observed for number of roots per plant in both these populations. Shoot dry weight in Faisalabad native and adapted population showed strong correlation with minimum temperature in 2015 and with maximum temperature in 2016. Root dry weight of Faisalabad adapted population in 2016 and Quetta adapted population in 2015 displayed negative correlation with maximum and minimum temperatures, respectively. Shoot and root MDA manifested strong negative correlations of Quetta adapted population for both the with minimum and maximum temperature. Claiming an increase or decrease in the temperature will inversely effect its content in roots and shoots of lemongrass (Table 3). As for shoot and root $\mathrm{H}_{2} \mathrm{O}_{2}$, Faisalabad native and Quetta adapted populations indicated strong negative correlations with maximum temperatures in 2015 while minimum temperature in 2016.

\section{DISCUSSION}

Environmental conditions in any location are the primed determinant of growth and productivity of any species. The plasticity in growth is greatly dependent upon the available climatic and edaphic factors, which greatly influence the growth performance. It is believed that abiotic and biotic factors increase plasticity of plants (Valladares et al., 2006). Phenotypic plasticity may be significant for the survival of plants in variable conditions as well as heterogeneous environments (Van-Kleunen and Fischer, 2007).

In this study to observe changes in the growth attributes the population growing in Faisalabad when shifted to Quetta for possible adaptability showed that a number of changes took place in the growth behavior. Almost similar was the case when Quetta population was adapted to Faisalabad. It was specifically noticed that Faisalabad lemongrass population adapted in Quetta exhibited quite a few morphological and biochemical changes. For instance, its leaves light green color in Faisalabad showed dark green color in Quetta (data not shown). Beside changes in leaf color, Faisalabad lemongrass population adapted in Quetta showed less number of roots although it gained more height had greater leaf area and manifested longer roots (Fig. 1). Cooler environment tends to favor greater leaf area at high altitudes (Kao and Chang, 2001). Longer roots outlined the xeric environment of Quetta and as such in water-deficit conditions roots act as sensors and transduce signals for better growth (Hamanishi and Campbell, 2011). Korner and Paulsen (2004) found that at high altitudes decrease in temperature particularly underground lower temperature can limit plant growth and root development as Quetta is located at higher altitude (1679 m.a.s.l.) cooler climate challenged the survival of the adapted population.

Considering the tiller formation, it was observed that Faisalabad lemongrass population lost the tendency to tiller profusely and produced less number of leaves when shifted to Quetta owing to a less humid and relatively cooler climate of Quetta compared to Faisalabad (Fig. 1). The Quetta population adapted in Faisalabad although grew successfully in both the experimental years; it did not show a remarkable change in height or leaf color. However, it indicated prolific root system, enhanced tillering but root length was decreased (Fig. 1). Enhanced tillering is associated with not only with the increased chances of survival but also results in increased dry weight of shoot and root (Fig. 1) during unfavorable conditions as has been documented in case of Italian ryegrass (Bartholomew and Williams, 2009). The changes appearing in different growth attributes show that cross-adaptability is particularly dependent on these changes in the growth traits. Besides the morphological attributes it is well established that prevailing subversive environmental conditions impinge oxidative damage on the plants. The data from this study revealed that as a representative ROS the production of $\mathrm{H}_{2} \mathrm{O}_{2}$ was enhanced in Faisalabad adapted and Quetta native populations in the months of summer in both shoot and root (Fig. 2). High temperature leads to enhanced ROS generation in plants (Königshofer et al., 2008). Frost and chilling conditions challenge the survival of plants and result in an outburst of ROS and enhanced lipid peroxidation (Paredes and Quiles, 2017). However, the Quetta adapted population and its counterpart in Faisalabad showed higher contents of MDA and $\mathrm{H}_{2} \mathrm{O}_{2}$ during winter months (Fig. 2). MDA content was found to be higher in plants at higher altitudes, due to the prevailing low temperature and high incidence of UVB (Grabherr, 1994). Thus, beside the edaphic, the climatic conditions of elevation also acted as a major factor challenging adaptation of lemongrass population from low (Faisalabad) to higher altitude (Quetta) and vice versa with native lemongrass population successfully adapted to the respective region. From the comparison of changes in growth and oxidants between the years, it was evident that both the Faisalabad and Quetta adapted populations indicated slight adjustment to the new environments in 2016

The production of ROS under adverse conditions may have profound influence on the changes in the photosynthetic pigments, although supporting evidence is scarce. The altered climatic conditions produce an imbalance in cellular energy, thus changing the redox state of the thylakoid lamellae. Of the Chl- $a$ and Chl- $b$, a higher maintenance of Chl- $a$ has been paid due attention while loss of Chl- $b$ is considered as a great stress 
Table 3. Possible associations of growth, oxidative stress and photosynthetic pigments attributes of native and adapted lemongrass populations with maximum and minimum temperature in Faisalabad and Quetta locations in 2015 and $2016(n=7)$.

\begin{tabular}{|c|c|c|c|c|c|}
\hline \multirow[t]{2}{*}{ Parameter } & \multirow{2}{*}{$\begin{array}{l}\text { Lemongrass } \\
\text { populations }\end{array}$} & \multicolumn{2}{|c|}{2015} & \multicolumn{2}{|c|}{2016} \\
\hline & & Max temp & Min temp & Max temp & Min temp \\
\hline Shoot length & Faisalabad adapted & $-0.612 \mathrm{~ns}$ & $-0.766^{*}$ & $-0.691 \mathrm{~ns}$ & $-0.494 n s$ \\
\hline \multirow[t]{3}{*}{ Root length } & Faisalabad native & $-0.754 *$ & $-0.783 *$ & $-0.652 \mathrm{~ns}$ & $-0.498 n s$ \\
\hline & Faisalabad adapted & $-0.813 *$ & $-0.804 *$ & $-0.892 * *$ & $-0.833^{*}$ \\
\hline & Quetta native & $-0.893 * *$ & $-0.871^{*}$ & $-0.905 * *$ & $-0.899 * *$ \\
\hline \multirow[t]{3}{*}{ No. of leaves plant ${ }^{-1}$} & Faisalabad native & $-0.089 \mathrm{~ns}$ & $-0.399 \mathrm{~ns}$ & $0.754 *$ & $0.900 * *$ \\
\hline & Faisalabad adapted & $-0.675 n s$ & $-0.793^{*}$ & $-0.895 * *$ & $-0.792 *$ \\
\hline & Quetta native & $-0.209 n s$ & $-0.186 n s$ & $-0.831 *$ & $-0.835 *$ \\
\hline \multirow[t]{2}{*}{ Leaf area plant ${ }^{-1}$} & Faisalabad adapted & $-0.956 * *$ & $-0.952 * *$ & $-0.964 * *$ & $-0.777 *$ \\
\hline & Quetta native & $-0.839 *$ & $-0.837^{*}$ & $-0.799 *$ & $-0.862 *$ \\
\hline No. of tillers plant ${ }^{-1}$ & Faisalabad adapted & $-0.746 n s$ & $-0.873^{*}$ & $-0.869 *$ & $-0.928 * *$ \\
\hline \multirow[t]{3}{*}{ No. of roots plant ${ }^{-1}$} & Faisalabad native & $-0.752 \mathrm{~ns}$ & $-0.938 * *$ & $-0.059 \mathrm{~ns}$ & $0.120 \mathrm{~ns}$ \\
\hline & Faisalabad adapted & $-0.880 * *$ & $-0.973 * *$ & $-0.872 *$ & $-0.929 * *$ \\
\hline & Quetta native & $-0.907 * *$ & $-0.889 * *$ & $-0.821 *$ & $-0.800 *$ \\
\hline \multirow{4}{*}{ SDW } & Faisalabad native & $-0.566 n s$ & $-0.797 *$ & $-0.712 *$ & $-0.585 n s$ \\
\hline & Faisalabad adapted & $-0.542 \mathrm{~ns}$ & $-0.769 *$ & $-0.821 *$ & $-0.679 n s$ \\
\hline & Quetta native & $-0.776^{*}$ & $-0.725 n s$ & $-0.715 n s$ & $-0.764 *$ \\
\hline & Quetta adapted & $-0.757 *$ & $-0.820 *$ & $0.187 \mathrm{~ns}$ & $0.240 \mathrm{~ns}$ \\
\hline \multirow{2}{*}{ RDW } & Faisalabad adapted & $-0.207 \mathrm{~ns}$ & $0.126 \mathrm{~ns}$ & $-0.772 *$ & $-0.609 n s$ \\
\hline & Quetta adapted & $-0.753 \mathrm{~ns}$ & $-0.756^{*}$ & $0.645 \mathrm{~ns}$ & $0.651 \mathrm{~ns}$ \\
\hline \multirow[t]{4}{*}{ CHL-A } & Faisalabad native & $0.658 \mathrm{~ns}$ & $0.873^{*}$ & $0.846^{*}$ & $0.913 * *$ \\
\hline & Faisalabad adapted & $0.438 \mathrm{~ns}$ & $0.716 \mathrm{~ns}$ & $0.918 * *$ & $0.844 *$ \\
\hline & Quetta native & $0.722 \mathrm{~ns}$ & $0.745 \mathrm{~ns}$ & $0.916 * *$ & $0.933 * *$ \\
\hline & Quetta adapted & $0.921 * *$ & $0.968 * *$ & $0.896 * *$ & $0.898 * *$ \\
\hline \multirow[t]{4}{*}{ CHL-B } & Faisalabad native & $0.269 \mathrm{~ns}$ & $0.594 \mathrm{~ns}$ & $0.927 * *$ & $0.855^{*}$ \\
\hline & Faisalabad adapted & $0.536 \mathrm{~ns}$ & $0.816^{*}$ & $0.833 *$ & $0.703 \mathrm{~ns}$ \\
\hline & Quetta native & $0.736 \mathrm{~ns}$ & $0.762 *$ & $0.923 * *$ & $0.934 * *$ \\
\hline & Quetta adapted & $0.785^{*}$ & $0.827 *$ & $0.784 *$ & $0.736 \mathrm{~ns}$ \\
\hline \multirow[t]{4}{*}{ Total chlorophylls } & Faisalabad native & $0.559 \mathrm{~ns}$ & $0.824 *$ & $0.927 * *$ & $0.921 * *$ \\
\hline & Faisalabad adapted & $0.496 \mathrm{~ns}$ & $0.776^{*}$ & $0.891 * *$ & $0.793^{*}$ \\
\hline & Quetta native & $0.737 \mathrm{~ns}$ & $0.762 *$ & $0.953 * *$ & $0.966 * *$ \\
\hline & Quetta adapted & $0.883 * *$ & $0.929 * *$ & $0.857 *$ & $0.836^{*}$ \\
\hline \multirow{2}{*}{ Chlorophyll $a: b$ ratio } & Faisalabad adapted & $-0.637 \mathrm{~ns}$ & $-0.919 * *$ & $0.402 \mathrm{~ns}$ & $0.627 \mathrm{~ns}$ \\
\hline & Quetta native & $-0.596 \mathrm{~ns}$ & $-0.610 \mathrm{~ns}$ & $-0.782 *$ & $-0.806^{*}$ \\
\hline \multirow[t]{4}{*}{ Carotenoids } & Faisalabad native & $-0.635 n s$ & $-0.823^{*}$ & $-0.835^{*}$ & $-0.671 \mathrm{~ns}$ \\
\hline & Faisalabad adapted & $0.627 \mathrm{~ns}$ & $0.915^{* *}$ & $0.839 *$ & $0.937 * *$ \\
\hline & Quetta native & $0.936 * *$ & $0.892 * *$ & $0.924 * *$ & $0.965 * *$ \\
\hline & Quetta adapted & $-0.850 *$ & $-0.890^{* *}$ & $-0.899 * *$ & $-0.898 * *$ \\
\hline \multirow[t]{3}{*}{ MDA Shoot } & Faisalabad adapted & $0.797^{*}$ & $0.870 *$ & $0.878^{* *}$ & $0.842 *$ \\
\hline & Quetta native & $0.942 * *$ & $0.941 * *$ & $0.885^{* *}$ & $0.906 * *$ \\
\hline & Quetta adapted & $-0.890 * *$ & $-0.909 * *$ & $-0.933 * *$ & $-0.940 * *$ \\
\hline \multirow[t]{3}{*}{ MDA Root } & Faisalabad adapted & $0.809 *$ & $0.830 *$ & $0.890 * *$ & $0.781 *$ \\
\hline & Quetta native & $0.943 * *$ & $0.940 * *$ & $0.887 * *$ & $0.878 * *$ \\
\hline & Quetta adapted & $-0.777 *$ & $-0.790 *$ & $-0.906 * *$ & $-0.899 * *$ \\
\hline \multirow[t]{4}{*}{$\mathrm{H}_{2} \mathrm{O}_{2}$ Shoot } & Faisalabad native & $-0.903 * *$ & $-0.697 \mathrm{~ns}$ & $-0.871 * *$ & $-0.749 n s$ \\
\hline & Faisalabad adapted & $0.637 \mathrm{~ns}$ & $0.830^{*}$ & $0.726 \mathrm{~ns}$ & $0.901 * *$ \\
\hline & Quetta native & $0.065 \mathrm{~ns}$ & $-0.018 \mathrm{~ns}$ & $0.892 * *$ & $0.934 * *$ \\
\hline & Quetta adapted & $-0.881 * *$ & $-0.890 * *$ & $-0.480 \mathrm{~ns}$ & $-0.310 \mathrm{~ns}$ \\
\hline \multirow[t]{4}{*}{$\mathrm{H}_{2} \mathrm{O}_{2}$ Root } & Faisalabad native & $-0.909 * *$ & $-0.957 * *$ & $-0.709 \mathrm{~ns}$ & $-0.782 *$ \\
\hline & Faisalabad adapted & $0.668 \mathrm{~ns}$ & $0.889 * *$ & $0.791 *$ & $0.809 *$ \\
\hline & Quetta native & $0.829 *$ & $0.751 \mathrm{~ns}$ & $0.923 * *$ & $0.961 * *$ \\
\hline & Quetta adapted & $-0.898 * *$ & $-0.907 * *$ & $-0.892 * *$ & $-0.892 * *$ \\
\hline
\end{tabular}

Significant at $* \mathrm{P}<0.05 ; * * \mathrm{P}<0.01$ and ns non-significant 
susceptibility indicator in different plants (Wahid, 2007; Rudra et al., 2008). Conversely, Koca et al. (2007) reported that Chl- $a$ is more susceptible under heat stress and can be degraded approximately 2 to 10 times faster than Chl- $b$. In this study it is found that the Quetta lemongrass population irrespective of being native or adapted in Quetta and Faisalabad, respectively manifested a greater Chl- $a$ content. On the other hand, Faisalabad population adapted in Quetta indicated a greater Chl- $a$ content than its counterpart in Faisalabad (Fig. 3). As already stated greater leaf area was observed in Quetta lemongrass populations (native and adapted); therefore exhibited an enhanced photosynthetic activity at higher altitudes (Hultine and Marshall, 2000; Bresson et al., 2011). The Chl- $a$ content was generally higher in the months of June, July and August, which decreased at the onset of winter up to peak winter season in adapted and native populations from both the locations (Fig. 3). Both the chlorophyll species declined under low temperature in spruce needle (Herbinger et al., 1999), while in pine and Quercus spp., winter season manifested reduced photochemical capacity of photosystem II (Oliveira and Penuelas, 2004).

As regards Chl- $b$ contents of both adapted and native population from both the locations, its content was always greater in Quetta than in Faisalabad, and indicated a decline in the winter months than the summer months (Fig. 3). This further led to increased total chlorophylls during progression of summer months. However, Chl- $a: b$ ratio was lesser under relatively suboptimal conditions of summer and winter (Fig. 3 ). Chlorophyll $a, b$ and their total contents vary from species to species and from season to season in plants (Hyyryläinen et al., 2015). These data revealed that the prevailing environmental conditions do have a great impact on the maintenance of chlorophyll contents where it was noted that Quetta environment was more favorable in maintaining higher chlorophyll contents than Faisalabad.

The carotenoid content was higher during winter in Faisalabad native and Quetta adapted population. Conversely, carotenoid content was higher during summer in Quetta native and Faisalabad adapted population (Fig. 3). Its greater accumulation in Quetta is assignable to harsh winter season there when the temperature dropped up to $-5^{\circ} \mathrm{C}$. An increase in carotenoid content plays a crucial role for the survival of the plants under subversive conditions (Spanò et al., 2017). Chlorophyll species, being susceptible to environmental stresses, show reduced light harvesting, whilst increase in the carotenoid contents may protect the photosynthetic apparatus from being destroyed (Hormaetxe et al., 2004; Salama et al., 2011). These roles of carotenoids are assignable to the fact that they act as scavengers of ROS produced during extreme conditions of temperature prevailing in any area (Rodrigues et al., 2012; Taiz et al., 2015).

Regression and correlations are important statistical tools used to find out trend of changes and interrelationships among different variables (Steel et al., 1996). In these studies, the changes in growth, oxidative stress and photosynthetic pigments were regressed and correlated against the prevailing temperature and relative humidity conditions in both the locations. It was known that relative humidity indicated no correlations with the growth, oxidative damage and photosynthetic pigment contents from both the locations and all populations (data not shown). However, prevailing maximum and minimum temperatures emerged to be sole determinants of changes in the adapted or native lemongrass populations (Table 3). The data supported the notion that cross-locational adaptability is strongly dependent upon the seasonal changes in the prevailing temperatures in any location.

Conclusion: Reduced growth of adapted populations in Quetta and Faisalabad was due to inability of these populations to thrive at new locations. The changes in the production of ROS and MDA indicated that the native populations were well adjusted to their original location while the adapted ones were not able to show reduced ROS and MDA contents. Improved carotenoid contents were clearly related to the severity of prevailing temperature. Enhanced carotenoid content may therefore be taken as index successful cross-adaptability in different populations of lemongrass. Correlations data showed that the temperature related enhanced ROS generation most likely had adverse effect on the leaf photosynthetic pigments. Lemongrass was quite successful in showing adaptation to the varied environment of Quetta and Faisalabad due to phenotypic and biochemical flexibility. This can be exploited for promoting this grass species in contrasting environments.

Acknowledgements: This paper is part of Ph.D. thesis of Kanval Shaukat. The first author is obliged to Higher Education Commission (HEC), Islamabad, Pakistan for sponsoring this research project under Indigenous Scholarship Scheme 5000 program (Phase-II, Batch II).

\section{REFERENCES}

Akhila, A. 2010. Essential oil-bearing grasses: The genus Cymbopogon. CRC Press, Boca Raton, Florida, USA.

Anderson, J.T., J.H. Willis and T. Mitchell-Olds. 2011. Evolutionary genetics of plant adaptation. Trends Genet. 27:258-266.

Andrew, R.L., I.R. Wallis, C.E. Harwood and W.J. Foley. 2010. Genetic and environmental contributions to variation and population divergence in a broad-spectrum foliar defense of Eucalyptus tricarpa. Ann. Bot. 105:707717.

Arnon, D.I. 1949. Copper enzyme in isolated chloroplasts. Polyphenoloxidase in Beta vulgaris. Plant Physiol. 24:115.

Barbosa, L.C.A., U.A. Pereira, A.P. Martinazzo, C. Álvares Maltha, R. Teixeira and E. de Castro Melo. 2008. Evaluation of the chemical composition of Brazilian 
commercial Cymbopogon citratus (D.C.) Stapf samples. Molecules 13:1864-1874.

Bartholomew, P.W. and R.D. Williams. 2009. Establishment of Italian ryegrass (Lolium multiflorum Lam.) by self-seeding as affected by cutting date and degree of herbage removal in spring in pastures of the southern Great Plains of the United States. Grass Forage Sci. 64:177-186.

Bresson, C.C., Y. Vitasse, A. Kremer and S. Delzon. 2011. To what extent is altitudinal variation of functional traits driven by genetic adaptation in European oak and beech? Tree Physiol. 31:1164-1174.

Chaudhary, Q.Z. and G. Rasul. 2004. Climatic classification of Pakistan. Sci. Vision 9:59-66.

Cramer, G.R., K. Urano, S. Delrot, M. Pezzotti and K. Shinozaki. 2011. Effects of abiotic stress on plants: A systems biology perspective. Plant Biol. 11:163-169.

Crispo, E. 2008. Modifying effects of phenotypic plasticity on interactions among natural selection, adaptation and gene flow. J. Evol. Biol. 21:1460-1469.

Dat, J., S. Vandenabeele, E. Vranova, M. Van Montagu, D. Inze and F. Van Breusegem. 2000. Dual action of the active oxygen species during plant stress responses. Cell. Mol. Life Sci. 57:779-795.

Davies, B.H. 1976. Carotenoids. In: Chemistry and Biochemistry of Plant Pigments, 2nd edition, T. W. Goodwin (Ed.), pp. 138-165. Academic Press, London.

Farooq, M., A. Wahid, N. Kobayashi, D. Fujita and S.M.A. Basra. 2009. Plant drought stress: Effects, mechanisms and management. Argon. Sustain. Dev. 29:185-212.

Gill, S.S., N.A. Anjum, R. Gill, S. Yadav, M. Hasanuzzaman, M. Fujita, P. Mishra, S.C. Sabat and N. Tuteja. 2015. Superoxide dismutase-mentor of abiotic stress tolerance in crop plants. Environ. Sci. Pollut. Res. 22:10375-10394.

Gong, M., B. Chen, Z.G. Li and G. Lih. 2001. Heat-shock induced cross adaptation to heat, chilling, drought and salt stress in maize seedlings and involvement of $\mathrm{H}_{2} \mathrm{O}_{2}$. J. Plant Physiol. 158:1125-1130.

Grabherr, G. 1994. Climate effects on mountain plants. Nature 369:448-450.

Grenier, S., P. Barre and I. Litrico. 2016. Phenotypic plasticity and selection: Nonexclusive mechanisms of adaptation. Scientifica 2016: 7021701.

Hamanishi, E.T. and M.M. Campbell. 2011. Genome-wide responses to drought in forest trees. Forestry 84:273-283.

Havaux, M. 1998. Carotenoids as membrane stabilizers in chloroplasts. Trends Plant Sci. 3:147-151.

Heath, R.L. and L. Packer. 1968. Photoperoxidation in isolated chloroplasts. Arch. Biochem. Biophys. 125:189-198.

Herbinger, K., M. Tauszi and D. Grill. 1999. Are winter adaptive changes in glutathione and chlorophyll contents in spruce needles triggered by low temperatures or short days? Plant Physiol. 39:171-174.
Hertel, T.W., M.B. Burz, B. Marshall and D.B. Lobell. 2010. The poverty implications of climate-induced crop yield changes by 2030. Global Environ. Change 20:577-585.

Hormaetxe, K., A. Hernández, J.M. Becerril and J.I. GarcíaPlazaola. 2004. Role of red carotenoids in photo-protection during winter acclimation in Buxus sempervirens leaves. Plant Biol. 6:325-332.

Hultine, K.R. and J.D. Marshall. 2000. Altitude trends in conifer leaf morphology and stable carbon isotope composition. Oecologia 123:32-40.

Hussain, A., G. Murtaza, A. Ghafoor, S.M.A. Basra, M. Qadir and M. Sabir. 2010. Cadmium contamination of soils and crops by long term use of raw effluent, ground and canal waters in agricultural lands. Int. J. Agric. Biol. 12:851-856.

Hyyryläinen, A., P. Rautio, M. Turunen and S. Huttunen. 2015. Seasonal and inter-annual variation in the chlorophyll content of three co-existing Sphagnum species exceeds the effect of solar UV reduction in a subarctic peatland. Springerplus 4:478.

Jump, A.S. and J. Penuelas. 2005. Running to stand still: Adaptation and the response of plants to rapid climate change. Ecol. Lett. 8:1010-1020.

Kao, W. and K. Chang. 2001. Altitudinal trends in photosynthetic rate and leaf characteristics of Miscanthus populations from central Taiwan. Aust. J. Bot. 49:509-514.

Kasote, D.K., S.S. Katyare, M.V. Hedge and H. Bae. 2015. Significance of antioxidant potential of plants and its relevance to therapeutic applications. Int. J. Biol. 11:982991.

Koca, N., F. Karadeniz and H.S. Burdulu. 2007. Effect of pH on chlorophyll degradation and colour loss in blanched green peas. Food Chem. 100:449-455.

Königshofer, H., H-W. Tromballa and H-G. Loppert. 2008. Early events in signaling high-temperature stress in tobacco BY2 cells involve alterations in membrane fluidity and enhanced hydrogen peroxide production. Plant Cell Environ. 31:1771-1780.

Körner, C. and J. Paulsen. 2004. A world-wide study of high altitude tree line temperatures. J. Biogeol. 31:713-732.

Lenoir, J., J.C. Gegout, P.A. Marquet, P. deRuffray and H. Brisse. 2008. A significant upward shift in plant species optimum elevation during the $20^{\text {th }}$ century. Sci. 320:17681771.

Lutts, S. 2001. Effects of multiple environmental constraints on plants: Before, during and after the stress. In: Plants under Environmental Stress, pp.174-175. Proceedings of the International Symposium, Timiryazev Institute of Plant Physiology, Moscow, Russia.

Mittler, R. 2002. Oxidative stress, antioxidants and stress tolerance. Trend Plant Sci. 7:405-410.

Murata, N., S. Takahashi, Y. Nishiyama and S.I. Allakhverdiev. 2007. Photoinhibition of photosystem II under environmental stress. Biochim. Biophys. ActaBioenergetics 1767:414-421. 
Ng, W.L., S.K. Yeap, N.S.M. Abu Bakar, W. Nurfatin, W.M. Jaafar and S.G. Tan. 2016. Multiplex PCR assays for species discrimination of Cymbopogon citratus (DC.) Stapf and C. nardus (L.) Rendle, two common 'Serai' (lemon grass) species in Peninsular Malaysia. Sains Malaysiana 45:323-327.

Nowak, R.S., E.S. Ellsworth and S.D. Smith. 2004. Functional responses of plants to elevated atmospheric $\mathrm{CO}_{2}$ : Do photosynthetic and productivity data from FACE experiments support early predictions? New Phytol. 162:253-280.

Oliveira, G. and J. Penuelas. 2004. Effects of winter cold stress on photosynthesis and photochemicalefficiency of PSII of the Mediterranean Cistus albidus L. and Quercus ilex L. Plant Ecol. 175:179-191.

Paredes, M. and M.J. Quiles. 2017. Chilling stress and hydrogen peroxide accumulation in Chrysanthemum morifolium and Spathiphyllum lanceifolium: Involvement of chlororespiration. J. Plant Physiol. 211:36-41.

Prasad, A., M. Anwar, D.D. Patra and D.V. Singh. 2001. Interactive effects of irrigation water salinity and soil fertility on salinity and sodicity build-up in soil and yield and cation composition of palmarosa and lemongrass. J. Ind. Soc. Soil Sci. 49:178-187.

Raffo, A., G.L. Malfa, V. Fogliano, G. Maiani, G. Quaglia. 2006. Seasonal variations in antioxidant components of cherry tomatoes (Lycopersicon esculentum cv. Naomi F1). J. Food Compos. Anal. 19:11-19.

Rather, R.N., A.A Wani, M. Kashtwari and Z.A. Beigh. 2018. Phenological shifts due to climate change and the associated conservation threats. Climate Change 4:80-86.

Rodrigues, E., L.R. Mariutti and A.Z. Mercadante. 2012. Scavenging capacity of marine carotenoids against reactive oxygen and nitrogen species in a membranemimicking system. Mar. Drugs 10:1784-798.

Rudra, G.S., B.C. Sarkar and U.S. Shivhare. 2008. Thermal degradation kinetics of chlorophyll in pureed coriander leaves. Food Bioprocess Technol. 1:91-99.

Salama, H.M.H., A. Ahlam, Al-Watban and A.T. Al-Fughom. 2011. Effect of ultraviolet radiation on chlorophyll, carotenoid, protein and proline contents of some annual desert plants. Saudi J. Biol. Sci. 18:79-86.

Sarfaraz, S., M.H. Arsalan and H. Fatima. 2014. Regionalizing the climate of Pakistan using Koppen classification system. Pak. Geograph. Rev. 69:111-132.

Sen, S. and S. Mukherji. 2000. Season-induced alterations in levels of antioxidants and polygalacturonase activity in tomato (Lycopersicon esculentum Mill.) fruit. J. Environ. Pollut. 7:303-308.

Shah, S.H.A. 1975. The structure of Quetta valley. Geol. Bull. 7:101-110.

Shi, M.M., S.G. Michalski, X.Y. Chen and W. Durka. 2011. Isolation by elevation: Genetic structure at neutral and putatively non-neutral loci in a dominant tree of subtropical forests, Castanopsis eyrei. PLoS One 6: e21302.

Slesak, I., M. Libik, B. Karpinska, S. Karpinski and Z. Miszalski. 2007. The role of hydrogen peroxide in regulation of plant metabolism and cellular signaling in response to environmental stresses. Acta Biochim. Pol. 54:39-50.

Song, Y., J. Yu and B. Huang. 2014. Elevated $\mathrm{CO}_{2}$-mitigation of high temperature stress associated with maintenance of positive carbon balance and carbohydrate accumulation in Kentucky bluegrass. PLoS One 9:e89725.

Spano, C., S. Bottegal, M.R. Castiglione and H.E. Pedranzani. 2017. Antioxidant response to cold stress in two oil plants of the genus Jatropha. Plant Soil Environ. 63:271-276.

Steel, R.G.D., J.H. Torrie and D.A. Dickey. 1996. Principles and Procedures of Statistics: A biometrical approach, $3^{\text {rd }}$ Ed., McGraw Hill Book Co., New York, USA.

Streb, P., S. Aubert, E. Gout, J. Feierabend and R. Bligny. 2008. Cross tolerance to heavy-metal and cold-induced photoinhibition in leaves of Pisum sativum acclimated to low temperature. Physiol. Mol. Biol. Plants14:185-193.

Taiz, L., E. Zeiger, I. M. Moller and A. Murphy. 2015. Plant Physiology and Development, $6^{\text {th }}$ Ed. Sinauer Associates Inc., Sunderland, Massachusetts, USA.

Valladares, F., D. Sanchez-Gomez and M.A. Zavala. 2006. Quantitative estimation of phenotypic plasticity: Bridging the gap between the evolutionary concept and its ecological applications. J. Ecol. 94:1103-1116.

Van-Kleunen, M. and M. Fischer. 2007. Progress in the detection of costs of phenotypic plasticity in plants. New Phytol. 176:727-730.

Velikova, V., I. Yordanov and A. Edreva. 2000. Oxidative stress and some antioxidant systems in acid rain-treated bean plants: Protective role of exogenous polyamines. Plant Sci. 151:59-66.

Vitasse, Y., C.C. Bresson, A. Kremer, R. Michalet and S. Delzon. 2010. Quantifying phenological plasticity to temperature in two temperate tree species. Funct. Ecol. 24:1211-1218.

Wahid, A. 2007. Physiological implications of metabolites biosynthesis in net assimilation and heat stress tolerance of sugarcane sprouts. J. Plant Res. 120:219-228.

Wahid, A., M. Farooq and K.H.M. Siddique. 2014. Implications of oxidative stress for crop growth and productivity. In: M. Pessarakli (ed.), Handbook of Plant and Crop Stress, $3^{\text {rd }}$ Ed. Taylor and Francis Press, New York, USA; pp.549-556.

Zhang, J.H., Y.P. Liu, Q.H. Pan, J.C. Zhan, X.Q. Wang and W.D. Huang. 2006. Changes in membrane-associated $\mathrm{H}^{+}-$ ATPase activities and amounts in young grape plants during the cross adaptation to temperature stresses. Plant Sci. 170:768-777. 